\title{
Research Report \\ FIRST EPISODE DEPRESSION IN WOMEN-A STUDY OF CLINICAL CHARACTERISTICS THROUGH THE FEMALE REPRODUCTIVE STAGES IN A RURAL TERTIARY CARE CENTER IN KERALA
}

\author{
Joice Geo $^{1^{*}}$, Jismi B Krishnan ${ }^{2}$, Mareen Benjamin ${ }^{3}$, Roy Abraham Kallivayali1 ${ }^{4}$ \\ ${ }^{1}$ Associate Professor in Psychiatry, Pushpagiri Medical College, Thiruvalla, Kerala \\ ${ }^{2}$ Junior Consultant in Psychiatry, Taluk Hospital, Chiriankeezh, Kerala \\ 3 junior Resident in Psychiatry, Pushpagiri Medical College, Thiruvalla, Kerala \\ ${ }^{4}$ Professor and HOD, Department of Psychiatry, Pushpagiri Medical College, Thiruvalla, Kerala \\ *Corresponding Address: drjoicegeo@gmail.com
}

Submitted on:27/11/2019 Published online: 27/12/2019

\section{ABSTRACT}

Background: The lifetime prevalence of major depressive disorders is $10-25 \%$ for women and 5$12 \%$ for men. Women are more prone to develop depressive episode from the period of menarche to the perimenopausal period. Relatively little research has been done on this.

Materials and methods: Female patients between the ages of 12 years to 55 years presenting in the outpatient department with first episode depressive symptoms are selected (ICD 10), and the number of patients presenting in different stages of the reproductive cycle - peri menarche, pregnancy, post-partum, post-abortion and perimenopausal are noted. Age at onset, severity of the illness, positive family history, presence of somatic and hypochondriac symptoms, and suicidal intent (Beck suicidal intent scale, Hamilton rating scale for depression) were noted.

Results and Discussion: Out of the total 120 patients, 53 were in the perimenopause state, 23 in the peri menarche, 5 in pregnancy, 14 in the post-partum, and 7 as post-abortion. The mean age of onset of depressive disorders was 36.7 years (SD- 13.67). The severity of the depressive episode is significantly higher towards the younger age group (<30years) $(\chi 2-24.315$, p-value.002) and the number of patients presenting with somatic symptoms are much higher towards the older age group (41-55years) $(\chi 2-13.760 \mathrm{p}$ value - .008). There is no significant difference in the presence of positive family history, hypochondriasis and suicidal intent among various age groups. Perimenopausal and peri menarche periods show a higher prevalence of depressive disorders during the female reproductive cycle.

Conclusion: There is a high prevalence of depression during female reproductive phases. More studies based on female reproductive hormonal changes and mood disorders are needed to prove the association.

Keywords: first episode depression, reproductive, women

Please cite this article as: Joice G, Jismi B K, Mareen B, Kallivayalil RA. First episode depression in women- a study of clinical characteristics through the female reproductive stages in a rural tertiary care center in Kerala. Kerala Journal of Psychiatry 2019;32(1): 39-45. doi: 10.30834/KJP.32.1.2019.178 


\section{INTRODUCTION}

Depression is a major mental disorder causing long term disability and functional impairment. It is more prevalent in women in India across all age groups. The proposed causes are the influence of female reproductive hormones during the reproductive years and the psychosocial stress due to gender disadvantage and the multiple roles played by Indian women. The average age of onset of depression is 31.9 years, in India. ${ }^{1}$ Although there has been evidence for some time of a gender difference in depression, relatively little research has examined for the same. ${ }^{2}$ The fluctuating levels of reproductive hormones have a strong influence on women's mental and physical health during the pre-menopausal and perimenopausal period. ${ }^{3}$

Women are more prone to develop depressive episode from the period of menarche to the perimenopausal period. Depression is the most common mental disorder among adolescent females with prevalence rates ranging from $15-20 \%$ among adolescents between the age of 14-19 years, and it is believed to be a major cause for adolescent suicide. Adolescents hesitate to seek psychiatric help and to disclose their feelings to their parents. ${ }^{4}$ However, adolescents, especially females, experience depressive symptoms more frequently than adolescent males.

For a long time, there is a concern about women experiencing symptoms of anxiety and depression during pregnancy and in the months following birth, and there is evidence of the effect of antidepressant in these women 5. Postpartum depression (PPD) among women is a common mental health concern.
Giving birth is a major life event in a woman's life, coupled with the increased responsibilities associated with the care of a newborn infant. ${ }^{6}$ The data from developing countries suggests that rates of depression in mothers of young infants exceed $25 \%$, and in some settings may be as high as $60 \%{ }^{7}$

There is an increased risk for depressive symptoms during the transition to menopause. it remains to be seen whether this period is one of increased risk for major depressive disorder, particularly for women who do not have a previous history of depression ${ }^{8}$ The changes in the levels of reproductive hormones could be the major cause for the increased prevalence of depressive disorders during the perimenopausal period.?. Relatively little research has been done on the relationship between stages in the female reproductive span and prevalence of depressive disorders, particularly in India.

\section{AIMS AND OBJECTIVES}

1) To determine the clinical characteristics and age of onset of first-episode depression in females in the age group of $12-55$ yrs.

2) To determine the distribution of first episode depression across with the various phases of female reproduction

3) To evaluate the severity, family history, suicidal intent, somatic symptoms, and hypochondriasis among depressed patients in various phases of the reproductive span

\section{MATERIALS AND METHODS:}

Women between the ages $12 \mathrm{yrs}$ to $55 \mathrm{yrs}$ who presented in the psychiatry outpatient department of Pushpagiri Institute of Medical 
Sciences \& Research Centre, Thiruvalla, Pathanamthitta District, Kerala, between the period $1^{\text {st }}$ September 2015 to $17^{\text {th }}$ June 2016, with the first episode of depression were selected for the study by consecutive sampling. Patients with other comorbid psychiatric disorders and major physical illnesses were excluded from the study. Informed written consent was obtained from each patient. The sociodemographic details were recorded for each patient. Depressive disorder was diagnosed based on the ICD-10 diagnostic criteria for depressive disorders and severity of suicidal intent was measured with the Beck suicide intent scale. The severity of the depressive episode, presence of somatic symptoms, and hypochondriasis were noted employing the Hamilton rating scale for depression.

Women of ages 12-16 years are taken as peri menarche. ${ }^{10}$ and $45-55$ years are considered as perimenopause. ${ }^{11}$ One year after delivery and six months after abortion are considered as post-partum and post-abortion respectively.

The number of patients presenting with depression during particular phases of female reproduction - peri menarche, pregnancy, post-partum, post-abortion and perimenopause were noted. Positive family history of mood disorders among first degree relatives was noted. The permission of the institutional ethical committee was taken.

\section{STATISTICAL ANALYSIS}

The data were analyzed with SPSS version 16.0 for windows. Mean, and the standard deviation was employed to describe continuous variables, while frequency distributions were obtained for categorical data. The Chi-square test was used to assess
Table 1: Marital and Work/Employment Status of women with depression $(n=120)$

\begin{tabular}{|c|c|c|}
\hline & Frequency & Percentage (\%) \\
\hline Married & 84 & 70 \\
Unmarried & 36 & 30 \\
Student & 18 & 15 \\
Working & 29 & 24.2 \\
Housewife & 73 & 60.8 \\
\hline
\end{tabular}

the significance of association for categorical variables.

\section{RESULTS}

Table 2. Mean age of onset of depression among women $(n=120)$

\begin{tabular}{|l|l|l|l|}
\hline $\begin{array}{l}\text { Disease } \\
\text { status }\end{array}$ & Mean age & No. & $\begin{array}{l}\text { Std. } \\
\text { Deviation }\end{array}$ \\
\hline Mild & 42.98 & 53 & 11.12 \\
Moderate & 35.81 & 26 & 14.20 \\
severe & 29.39 & 41 & 12.72 \\
Total & 36.78 & 120 & 13.67 \\
\hline
\end{tabular}

As per table 2 mean age of onset of firstepisode depression is 36.78 years (SD13.672). In table 3 out of 120 patients, 57 $(47.5 \%)$ are of age above 41 years. The highest percentage of patients belongs to the perimenopausal age group (44.4\%), and next is peri menarche (19.2\%). Table 4 shows the number of patients suffering from severe depressive disorders is significantly higher in the younger age group (below 30 years) compared with the elder age group (4055years).There is a significantly higher number of patients towards the elder age 
group (41-55years) presented with somatic symptoms comparing with the younger age

Table 3: Distribution of $1^{\text {st }}$ episode depression in women among various groups

\begin{tabular}{|l|c|}
\hline & Frequency (\%) \\
\hline Age category(years) & \\
$12-20$ & $20(16.7 \%)$ \\
$21-30$ & $25(20.8 \%)$ \\
$31-40$ & $18(15.0 \%)$ \\
$41-50$ & $34(28.3 \%)$ \\
$51-55$ & $23(19.2 \%)$ \\
Reproductive phases & \\
Peri menarche & $23(19.2 \%)$ \\
Pregnancy & $05(4.2 \%)$ \\
Postpartum & $14(11.7 \%)$ \\
Post-abortion & $07(5.8 \%)$ \\
Perimenopausal & $53(44.4 \%)$ \\
\hline
\end{tabular}

group (below 30 years). Table. 5 shows there is no significant difference in suicidal intent, presence of hypochondriasis and positive family history among various age groups.

\section{DISCUSSION}

A total of 120 women presenting with firstepisode depression were evaluated. Out of 120 patients, $57(47.5 \%)$ are of age above 41 years (table 2).In a study in central Travancore, Kerala (very close to the locality of the current study) by Archana PS et al. shows $26.09 \%$ prevalence of depression among middle-aged women in the rural area of Kerala. ${ }^{12}$ Of them 45 patients were below 30 years $(37.5 \%) .18$ of them belong to 31 to 40 years (15\%). The mean age at onset is 36.78 years in the current study. According to the study done by Neenah Bohra et al., the mean age onset of depression was 31.9 years. And this study shows the prevalence rate of depression in women range from 1.5 to 37.7/1000 and a higher rate has been reported in rural areas of India. ${ }^{1}$

In the current investigation, women in the perimenopausal stage were significantly more likely to present with depression (53 patients) in the outpatient department. The prevalence of depression is more in menopausal transition (18.2\%) and in post- menopause period $(19.6 \%)$ than the premenopausal period(14.5\%). ${ }^{13}$ It had been shown earlier that Perimenopause had been recognised as a period of high risk for depressive and anxiety disorders. The reason may be the strong influence of sex hormones and their fluctuation during the reproductive cycle. ${ }^{3}$ In the study by Jagtap et al. a total of 108 perimenopausal women were evaluated, out of which 48 (44.44\%) had psychiatric disorders including 34 (31\%) women with major depressive disorder (MDD), 8 (7\%) women having anxiety disorder, while 6 (5\%) women were diagnosed as having MDD with comorbidity. ${ }^{14}$

In this study, 23 patients are of peri-menarche age category(table3). Increased prevalence of depression during adolescence probably corresponds to the hormonal changes in this age. ${ }^{11}$ comment on other issues academic,interpersonal,etc. There is an association with the age of onset of depression in females and menarche. ${ }^{10}$

There are 14 patients post-partum, 7 patients with pregnancy and 5 patients are postabortion(table 3). Comment on the implications of depression in this time period.The prevalence of depression during pregnancy was found to be $9.18 \%$ (ranges 
Table 4: Age at onset and severity of the depressive disorder and somatic symptoms

\begin{tabular}{|c|c|c|c|c|}
\hline \multirow{2}{*}{$\begin{array}{c}\text { Age category } \\
\text { (years) }\end{array}$} & \multicolumn{3}{|c|}{ Disease status } & \multirow[t]{2}{*}{ Somatic symptoms } \\
\hline & Mild & Moderate & Severe & \\
\hline $12-20$ & $3(15 \%)$ & $5(25 \%)$ & $12(60 \%)$ & $3(15 \%)$ \\
\hline $21-30$ & $6(24 \%)$ & $6(24 \%)$ & $13(52 \%)$ & $7(28 \%)$ \\
\hline $31-40$ & $7(38.9 \%)$ & $4(22.2 \%)$ & $7(38.9 \%)$ & $1(5.6 \%)$ \\
\hline $41-50$ & $22(64.7 \%)$ & $6(17.6 \%)$ & $6(17.6 \%)$ & $16(47.1 \%)$ \\
\hline$>50$ & $15(65.2 \%)$ & $5(21.7 \%)$ & $3(13 \%)$ & $10(43.5 \%)$ \\
\hline \multirow[t]{2}{*}{ Total } & $53(44.2 \%)$ & $26(21.7 \%)$ & $41(34.2 \%)$ & $37(30.8 \%)$ \\
\hline & & $x 2-24.315$ & & $\begin{array}{c}x 2-13.760 \\
\text { p value }-0.008\end{array}$ \\
\hline
\end{tabular}

Table 5: Age at onset and suicidal intent, hypochondriacal symptoms and family history

\begin{tabular}{|c|c|c|c|}
\hline & Suicidal intent (Beck>6) & $\begin{array}{c}\text { Hypochondriac symptoms } \\
\text { (Hamilton rating scale) }\end{array}$ & $\begin{array}{c}\text { Positive family history of } \\
\text { mood disorders }\end{array}$ \\
\hline $12-20$ & $4(20 \%)$ & $3(15 \%)$ & $8(23.5 \%)$ \\
$21-30$ & $7(28 \%)$ & $4(16 \%)$ & $4(11.76 \%)$ \\
$31-40$ & $4(22.2 \%)$ & $3(16.7 \%)$ & $6(17.64 \%)$ \\
$41-50$ & $6(17.6 \%)$ & $12(35.3 \%)$ & $10(29.41 \%)$ \\
$>50$ & $2(8.7 \%)$ & $10(43.5 \%)$ & $6(17.64 \%)$ \\
Total & $23(19.2 \%)$ & $32(26.7 \%)$ & $34(28.33 \%)$ \\
\hline & $\mathrm{X}^{2}-3.055$ & $\mathrm{X}^{2}-8.385$ & $\mathrm{X}^{2}-3.512$ \\
& $\mathrm{p}$ value -0.549 & $\mathrm{p}$ value -0.078 & $\mathrm{p}$ value -0.476 \\
\hline
\end{tabular}

from 4 to $20 \%$ ) out of 185 women in a crosssectional survey carried out in Mumbai. ${ }^{15}$.
There is a high prevalence of depression in pregnant women according to the study done 
by Bennet et al. ${ }^{16}$ In the study by Katherine L Wisner et al., with a period prevalence of $21.19 \%$ the year after birth, depression is a frequent complication of childbearing. 18

The number of patients with severe depressive disorders is significantly higher in the younger age group (below 30 years) compared with the elder age group (4055years) [table 4]. Comment on possible management implications. The reason behind this finding might be the possibility of underlying bipolarity in the younger age group. As per the study was done by Peter $\mathrm{R}$ Joyce et al. the commonest age of onset of Bipolar disease is $15-19$ years. ${ }^{19}$

According to table 5, there are no significant differences in suicidal intent among women with depressive disorders in various age groups . As per the Swiss study by Steck et al. suicide intent is equally prevalent in between the ages $16-45$ years. ${ }^{16}$

In table 4, there is a significantly higher number of patients towards the older age group (41-55years) presenting with somatic symptoms compared with, the younger age group (below 30 years). This is an interesting finding, but could not get much literature on this aspect. As per table 5, there is no significant difference in the presence of hypochondriasis among the various age groups. As per the study by Tomlinson et al., somatic symptoms are commonly seen in women associated with depression than men. ${ }^{17}$ According to table 5, 34 patients show a positive family history, but there are no significant differences in the distribution of positive family history among various age groups. Since the sample selected was women presenting with first-episode depression, it could not include pre-menstrual dysphoric disorder.

\section{CONCLUSION}

There is a strong association between the onset of major depressive disorders and the female reproductive phases. The study demonstrates that a significantly higher number of women presented with the first episode of depression in the peri menarche and perimenopausal stages of their reproductive cycles. Studies with a larger sample size examining hormonal profiles and putative environmental risk factors may shed some light on the aetiological mechanisms leading to the high prevalence of depression in women across the life span.

Discuss the implications of management at the individual levels and organization of mental health services in the light of these findings.

\section{Financial support and sponsorship}

Nil.

\section{Conflicts of interest}

There are no conflicts of interest.

\section{REFERENCES}

1. Bohra N, Srivastava S, Bhatia M. Depression in Women in Indian Context. Vol. 57, Indian Journal of Psychiatry. 2015. p. 239-45.

2. Petersen AC, Sarigiani PA, Kennedy RE. Adolescent depression: Why more girls? J Youth Adolesc. 1991 Apr;20(2):247-71.

3. Osborne LM, Hermann A, Burt V, Driscoll K, Fitelson E, Meltzer-Brody S, et al. Reproductive psychiatry: The gap between clinical need and education. Am J Psychiatry. 2015;172(10):946-8.

4. Khalil AH, Rabie MA, Abd-El-Aziz MF, Abdou TA, El-Rasheed AH, Sabry WM. Clinical characteristics of depression among adolescent females: a cross-sectional study. Child Adolesc Psychiatry Ment Health. 2010 Oct 10;4(1):26.

5. Dunkel Schetter C, Tanner L. Anxiety, 
depression and stress in pregnancy: implications for mothers, children, research, and practice. Curr Opin, Psychiatry. 2012 Mar;25(2):141-8.

6. Van Vo T, Hoa TKD, Hoang TD. Postpartum Depressive Symptoms and Associated Factors in Married Women: A Cross-sectional Study in Danang City, Vietnam. Front public Heal. 2017;5:93.

7. Fitelson E, Kim S, Baker AS, Leight K. Treatment of postpartum depression: clinical, psychological and pharmacological options. Int J Women's Health. 2010 Dec 30;3:1-14.

8. Cohen LS, Soares CN, Vitonis AF, Otto MW, Harlow BL, R K, et al. Risk for New Onset of Depression During the Menopausal Transition. Arch Gen Psychiatry. 2006 Apr 1;63(4):385.

9. Freeman EW, Sammel MD, Lin H, Nelson DB, CJ R, KC, et al. Associations of Hormones and Menopausal Status With Depressed Mood in Women With No History of Depression. Arch Gen Psychiatry. 2006 Apr 1;63(4):375.

10. Tondo L, Pinna M, Serra G, De Chiara L, Baldessarini RJ. Age at menarche predicts age at onset of major affective and anxiety disorders. Vol. 39, European Psychiatry. 2017. p. 80-5.

11. Albert PR. Why is depression more prevalent in women? Vol. 40, Journal of Psychiatry and Neuroscience. 2015. p. 219-21.

12. PS A, Das S, Philip S, Philip RR, Joseph J, Punnoose VP, et al. Prevalence of depression among middle aged women in the rural area of Kerala [Internet]. Vol. 29, Asian Journal of Psychiatry. 2017. p. 154-9.

13. Tang R, Luo M, Li J, Peng Y, Wang Y, Liu B, et al. Symptoms of anxiety and depression among
Chinese women transitioning through menopause: findings from a prospective community-based cohort study. Fertil Steril [Internet]. 2019 Dec 1;112(6):1160-7114. Available from: https://doi.org/10.1016/j.fertnstert.2019.08.005

14. Jagtap B, Prasad BS V., Chaudhury S. Psychiatric morbidity in perimenopausal women. Ind Psychiatry J. 2016;25(1):86.

15. Ajinkya S, Jadhav P, Srivastava N. Depression during pregnancy: Prevalence and obstetric risk factors among pregnant women attending a tertiary care hospital in Navi Mumbai Industrial psychiatry journal. 2013.

16. Bennett $\mathrm{HA}^{1}$, Einarson A, Taddio A, Koren $G$, Einarson TRPrevalence of Depression During Pregnancy Systematic Review Obstet Gynecol. 2004 Apr;103(4):698-7

17. Steck N, Egger M, Zwahlen M. Assisted and unassisted suicide in men and women: Longitudinal study of the Swiss population. Vol. 208, British Journal of Psychiatry. 2016. p. 48490.

18. Wisner KL, Sit DKY, McShea MC, Rizzo DM, Zoretich RA, Hughes CL, et al. Onset timing, thoughts of self-harm, and diagnoses in postpartum women with screen-positive depression findings. JAMA Psychiatry. 2013;70(5):490-8.

19. Joyce PR. Age of onset in bipolar affective disorder and misdiagnosis as schizophrenia. Vol. 14, Psychological Medicine. 1984. p. 145-9. 